\title{
Osteoma of mastoid temporal bone
}

\author{
Gowri Sankar M. ${ }^{1}$, Somanath B. M. ${ }^{2}$, Raveendra P. Gadag ${ }^{2}$, Manu C. B. ${ }^{1}$, Nagaraj M. ${ }^{3}$ \\ Department of ENT, ${ }^{1}$ JIPMER, Puducherry, ${ }^{2}$ KIMS, Hubli, ${ }^{3}$ SSMC, Davangere, Karnataka India \\ Received: 16 April 2018 \\ Revised: 28 May 2018 \\ Accepted: 29 May 2018 \\ *Correspondence: \\ Dr. Somanath B. M., \\ E-mail: mgs21000@gmail.com \\ Copyright: (C) the author(s), publisher and licensee Medip Academy. This is an open-access article distributed under \\ the terms of the Creative Commons Attribution Non-Commercial License, which permits unrestricted non-commercial \\ use, distribution, and reproduction in any medium, provided the original work is properly cited.
}

\begin{abstract}
Osteoma is a benign slow growing bone tumour with predominance in long bones, and is rare in the skull. They are a rare occurrence in the mastoid temporal bone, being usually asymptomatic and treated mainly for cosmetic reasons. We report a case of a young female who presented with a history of swelling in the left post aural region since 10 years. Swelling was gradually increasing in size and was painless. Patient underwent excision of the tumour without any significant complication. As per our knowledge this appears to be the largest tumour reported in literature. The clinical presentation and radiological features of osteoma are characteristic but differential diagnosis should include eosinophilic granuloma, giant cell tumour, monostotic fibrous dysplasia, solitary variant of multiple osteoma, and osteoblastic metastasis. Osteomas present on the mastoid or squamous portion of the temporal bone need to be dealt for cosmetic purposes or if they are causing symptoms, while surgery should include careful removal of periosteal cover and safe margin of the mastoid cortex around it.
\end{abstract}

Keywords: Osteoma, Mastoid temporal bone, Temporal bone tumours, Post aural swelling

\section{INTRODUCTION}

Osteoma of the temporal bone is a rare entity with occurrence of $0.1 \%$ to $1 \%$ of all benign tumors of the cranial cap. ${ }^{1,2}$ They have been reported in all portions of the temporal bone, including squama, mastoid, internal and external auditory meatus, glenoid cavity, middle ear, Eustachian tube, petrous apex and styloid process. ${ }^{2-7}$

\section{CASE REPORT}

An 18-year-old female presented with the complaints of left post aural swelling for 10 years. There was no history of tinnitus, ear discharge, hearing loss or facial palsy.

Swelling was gradually increasing in size and painless. There was no history of trauma, headache, dizziness. Clinical examination of the patient revealed a solitary immobile spherical swelling measuring $4.5 \times 4.5 \mathrm{cms}$ in the left post aural region (Figure 1) which was non tender, smooth surfaced, with well-defined margins. Swelling was bony hard in consistency, skin over swelling was normal. Rest of the otologic examination, audiometric evaluation and routine laboratory investigations were normal.

A high resolution computed tomography (HRCT) temporal bone (Figure 2) revealed a well demarcated sclerotic mass in left mastoid part of temporal bone measuring $4 \mathrm{~cm} \times 4 \mathrm{~cm}$, originating from outer table of the skull with no evidence of destruction of the inner table or intracranial extension.

Patient was taken up for excision of swelling under general anesthesia. Modified post aural incision was taken over the swelling, and the lesion was found to have a broad base (Figure 3), which was thinned out using a drill and removed in toto. Edges were rounded off with a 
polishing burr and the wound was closed in layers (Figure 4).

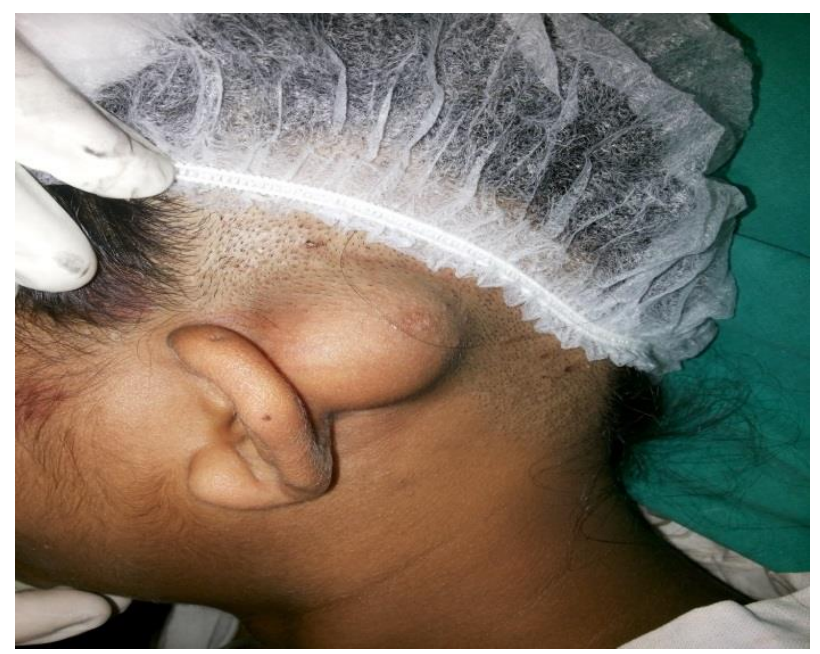

Figure 1: Pre-operative image demonstrating left post aural swelling.

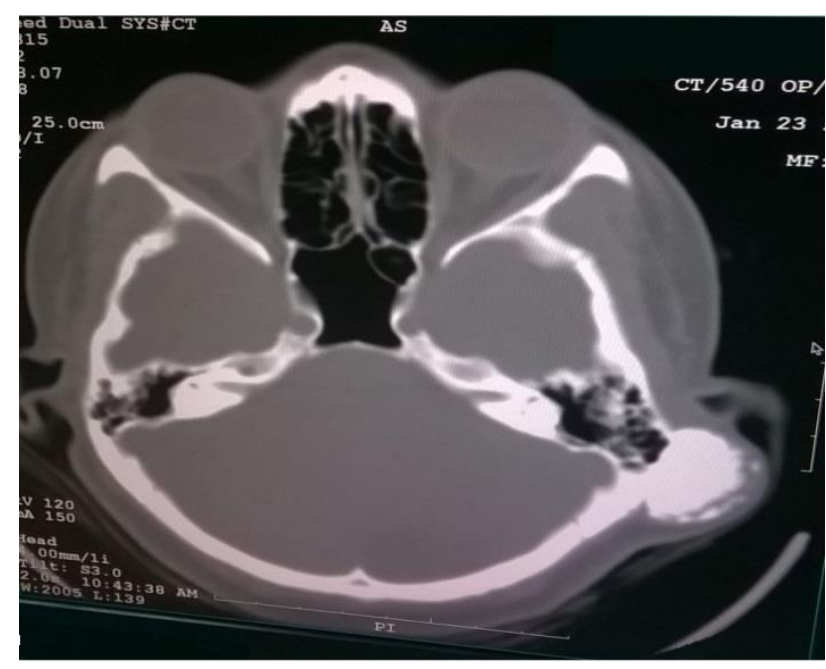

Figure 2: HRCT temporal bone demonstrating osteoma of left mastoid temporal bone.

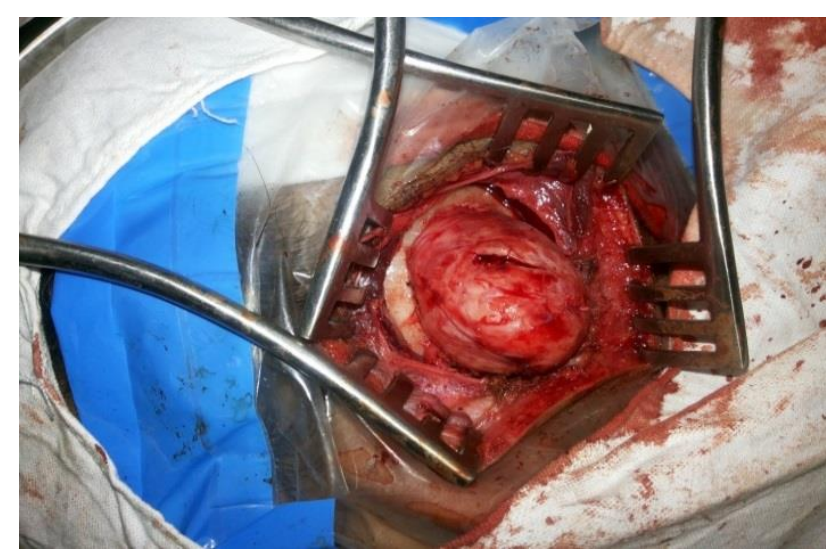

Figure 3: Intra operative view of osteoma of left temporal bone.

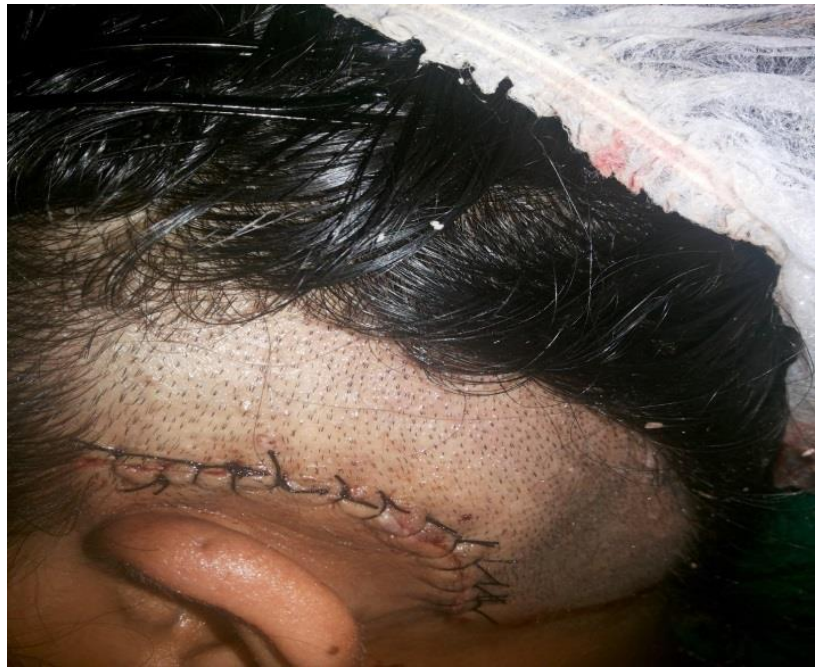

Figure 4: Immediate post-operative view of left mastoid region.

The gross specimen (Figure 5) was smooth, ivory white in appearance, ovoid shaped, and measuring $4.2 \mathrm{~cm} \times 4.4$ $\mathrm{cm}$ in size. Patient recovered without any complications. Histopathological examination showed it to be osteoma composed of compact bone and there was no recurrence in the 1 year follow up period.

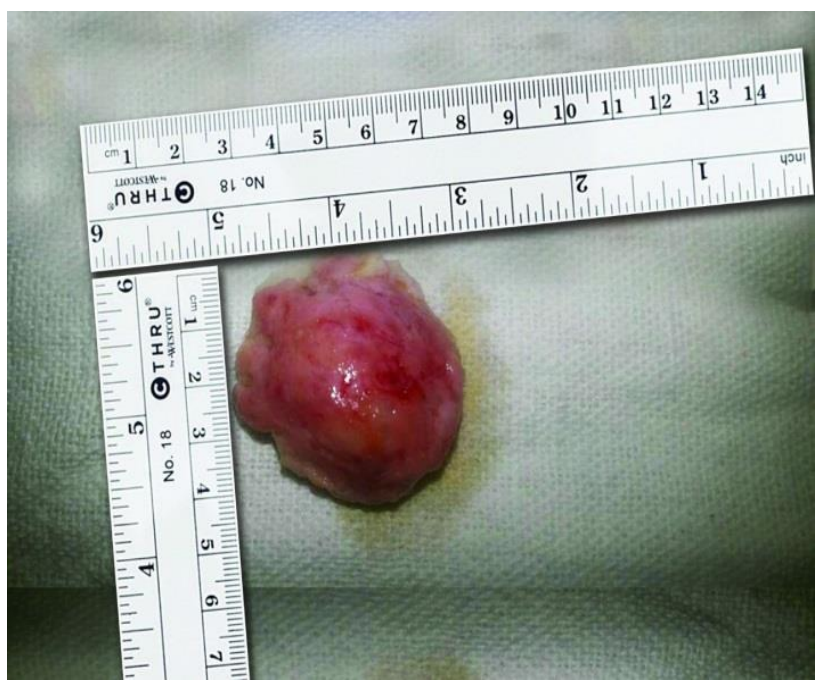

Figure 5: Excised specimen of approximate size $4.2 \times 4.4 \mathrm{cms}$.

\section{DISCUSSION}

Osteoid osteoma being a primary bone tumor accounting for $10 \%$ of all primary bone tumors, mostly occurs in long bones. ${ }^{7}$ In the skull, it mainly affects the frontoethmoid region, very uncommonly affecting the temporal bone. Within the temporal bone, common site of occurrence is the external auditory canal, being uncommon in the middle ear, and those in mastoid region being rarer. ${ }^{2}$ It is most frequently seen in teenagers and young adults and is very rare after 30 years of age. 
Furthermore, it is reported in literature that temporal bone osteomas occur twice as often in females, whereas osteomas of external auditory canal occur twice as often in males. ${ }^{8}$

The exact origin of osteoid osteoma has not been identified as yet. According to Haymann, osteomas were a result of alteration in the growth of the cranial bones. ${ }^{9,10}$ Freidberg postulated, it occurred as a result of trauma which induced periostitis. ${ }^{11}$ Histologically three types of mastoid osteomas have been described, based on structural characteristics. $^{12,13}$

Compact: The most common type. It consists of dense, compact and lamellar bone, with few vessels and Haversian canal systems within. Those with dense sclerotic bone are called ivory osteoma. Compact osteoma has a wider base and is slow growing.

Cartilaginous: Comprising bony and cartilaginous elements

Spongy: Rare type. Comprised of spongy bone and fibrous cell tissue, with tendency to expand to the diploe and involving the internal and external lamina of the affected bone. These have bone marrow and are also known as cancellous osteomas. They are more likely to be pedunculated and grow relatively faster.

Mixed: Mixture of spongy and compact types. ${ }^{13}$

These tumours are usually asymptomatic and are unsuspected X-ray findings, except for cortical lesions that are seen initially as cosmetic deformities. The main presenting complaint is headache, and is usually out of proportion to the size of the tumor. Pain is the other main presenting symptom of osteoid osteoma, which increases in the night and is relieved by salicylates. The lack of pain in osteoid osteoma has been reported in only $1.6 \%$ in a large review and was attributed to the lack of a hard shell or nerve endings around the lesion.

On computed tomography, osteoid osteoma typically demonstrates fusiform sclerotic cortical thickening in the shaft of long bones. A characteristic radiolucent area measuring $<1 \mathrm{~cm}$ in diameter and representing the lesion itself is usually within the centre of the area of sclerosis and harbors central calcification in approximately 50\% cases. $^{14,15}$

Surgical treatment of an osteoma is indicated when it is symptomatic and for cosmetic purposes. ${ }^{16}$ It may produce external deformity and push the pinna forward. If located in the external auditory canal, it may lead to occlusion, progressing to chronic external otitis (30\% of the cases) and conductive hearing loss. ${ }^{6}$ Temporal osteomas have been found to produce intracranial complications, justifying surgical removal.
Excision is not mandatory, but if performed, the surgery should include careful removal of periosteal cover and safe margin of the mastoid cortex around it. ${ }^{12}$ If the tumor is close to significant structures such as bony labyrinth and facial nerve canal, a subtotal excision ensures preservation of function. According to Guerin and colleagues, the early surgical intervention has been indicated to prevent voluminous growth and possible risk of complications in the surgical procedure. ${ }^{17}$ Surgical complications include recurrence, facial nerve palsy, sigmoid sinus damage and sensorineural hearing loss. Our patient was subjected to total excision of the lesion, with excellent aesthetic and curative results. As per our knowledge this appears to be the largest osteoma of the mastoid cortex reported in literature.

The clinical presentation and radiological features of osteoma are characteristic but differential diagnosis should include eosinophilic granuloma, giant cell tumour, monostotic fibrous dysplasia, solitary variant of multiple osteoma, and osteoblastic metastasis. ${ }^{11}$ One should also rule out Gardner's syndrome in patients presenting with large skull osteomas.

Recurrence is uncommon and malignant transformation has not been reported in the medical literature. ${ }^{6}$

\section{CONCLUSION}

Osteomas are rare tumors of temporal bone and should be addressed as per the symptoms of the patient. Osteoma presenting within the ear needs to be dealt carefully, for fear of damage to vital structures. Osteomas present on the mastoid or squamous portion of the temporal bone need to be dealt for cosmetic purposes or if they are causing symptoms, while surgery should include careful removal of periosteal cover and safe margin of the mastoid cortex around it.

Funding: No funding sources

Conflict of interest: None declared

Ethical approval: Not required

\section{REFERENCES}

1. Ünal ÖF, Tosun F, Yetışer S, Dündar A. Osteoma of the middle ear. Int $\mathrm{J}$ Pediatr Otorhinolaryngol. 2000;52(2):193-5.

2. Schartz CW. Cranial osteomas from a roentgenologic viewpoint. Am $\mathrm{J}$ Roentgenol. 1940,44:188-96.

3. Burton DM, Gonzalez C. Mastoid osteomas. Ear Nose Throat J. 1991;70:161-2.

4. D'Ottvai LR, Piccirillo E, De Sanctis S, Cenqua N. Mastoid osteomas: review of the literature and presentation of two clinical cases. Acta Otorrinolaringol Ital. 1997;17:136-9.

5. Gil Tutor E. Osteoma of the mastoid. Case report. An Otorrinolaringol Ibero Am. 1991;18:325-30. 
6. Van Dellen JR. A mastoid osteoma causing intracranial complications: a case report. S Afr Med J. 1977;51:597-8.

7. Johnson PT, Fayad LM, Frassica FJ, Fishman EK. Computed tomography of the bones of the foot: neoplastic disease. J Computer Assisted Tomography. 2009;33(3):436-43.

8. Ohhashi M, Terayama Y, Mitsui, H. Osteoma of the Temporal Bone: A Case Report. Nippon Jibiinkoka Gakkai Kaiho. 1984;87:590-595

9. Tran LP, Grungfast KM, Selesnick SH. Benign Lesions of the External Auditory Canal. Otolaryngologic Clin North Am. 1996;29:807-25.

10. Fisher EW, McManus TC. Surgery of the External Auditory Canal Exostoses and Osteomata. J Laryngol Otol. 1994;108:106-10.

11. Friedberg SA. Osteoma of Mastoid Process. Arch Otolaryngol Head Neck Surg. 1938;28:20-6.

12. Varshney S. Osteoma of temporal bone. Indian $\mathbf{J}$ Otol. 2001;7:91-2.
13. Probost LE, Shanken L, Fox R. Osteoma of the mastoid bone. J Otolaryngol. 1991;20:228-30.

14. Schulman L, Dorfman HD Nerve fibers in osteoid osteoma. J Bone Joint Surg Am. 1970;52:1351-6.

15. Singh I, Agarwal AK, Agarwal S, Yadav SPS. Giant osteoma of the mastoid bone. Indian $\mathbf{J}$ Otol. 1999;5:97-8.

16. Gupta OC, Samanth IC. Osteoma of the mastoid bone. Laryngoscope. 1972;82:172-6.

17. Guérin N, Chauveau E, Julien M, Dumont JM, Meignarques E. Osteoma of the mastoid bone: report of two cases. Laryngol Otol Rhinol. $1996 ; 117: 127-32$.

Cite this article as: Gowri Sankar M, Somanath BM, Gadag RP, Manu CB, Nagaraj M. Osteoma of mastoid temporal bone. Int J Otorhinolaryngol Head Neck Surg 2018;4:1097-100. 